\title{
Intragenic tandem repeat variation between Legionella pneumophila
} strains

\author{
David A Coil1 ${ }^{1}$, Liesbeth Vandersmissen ${ }^{1}$, Christophe Ginevra ${ }^{2,3,4}$, \\ Sophie Jarraud ${ }^{2,3,4}$, Elke Lammertyn ${ }^{1}$ and Jozef Anné*1
}

Address: ${ }^{1}$ Laboratory of Bacteriology, Rega Institute for Medical Research, Katholieke Universiteit Leuven, Minderbroedersstraat 10, B-3000 Leuven, Belgium, 22Université de Lyon, Université Lyon1, LYON, F-69365, France, ${ }^{3}$ INSERM, U851, 21 Avenue Tony Garnier, Lyon, F-69007, France and ${ }^{4}$ Hospices Civils de Lyon, Centre National de Référence des légionelles, Faculté de Médecine Laënnec, France

Email: David A Coil - david.coil@rega.kuleuven.be; Liesbeth Vandersmissen - liesbeth.vandersmissen@rega.kuleuven.be; Christophe Ginevra - christophe.ginevra@univ-lyon1.fr; Sophie Jarraud - sophie.jarraud@univ-lyon1.fr;

Elke Lammertyn - elke.lammertyn@lrd.kuleuven.be; Jozef Anné* - jozef.anne@rega.kuleuven.be

* Corresponding author

Published: 10 December 2008

BMC Microbiology 2008, 8:218 doi:10.1186/147/-2180-8-218
Received: 22 April 2008

Accepted: 10 December 2008

This article is available from: http://www.biomedcentral.com//47/ -2/80/8/218

(C) 2008 Coil et al; licensee BioMed Central Ltd.

This is an Open Access article distributed under the terms of the Creative Commons Attribution License (http://creativecommons.org/licenses/by/2.0), which permits unrestricted use, distribution, and reproduction in any medium, provided the original work is properly cited.

\begin{abstract}
Background: Bacterial genomes harbour a large number of tandem repeats, yet the possible phenotypic effects of those found within the coding region of genes are only beginning to be examined. Evidence exists from other organisms that these repeats can be involved in the evolution of new genes, gene regulation, adaptation, resistance to environmental stresses, and avoidance of the immune system.

Results: In this study, we have investigated the presence and variability in copy number of intragenic tandemly repeated sequences in the genome of Legionella pneumophila, the etiological agent of a severe pneumonia known as Legionnaires' disease. Within the genome of the Philadelphia strain, we have identified 26 intragenic tandem repeat sequences using conservative selection criteria. Of these, seven were "polymorphic" in terms of repeat copy number between a large number of $L$. pneumophila serogroup I strains. These strains were collected from a wide variety of environments and patients in several geographical regions. Within this panel of strains, all but one of these seven genes exhibited statistically different patterns in repeat copy number between samples from different origins (environmental, clinical, and hot springs).

Conclusion: These results support the hypothesis that intragenic tandem repeats could play a role in virulence and adaptation to different environments. While tandem repeats are an increasingly popular focus of molecular typing studies in prokaryotes, including in L. pneumophila, this study is the first examining the difference in tandem repeat distribution as a function of clinical or environmental origin.
\end{abstract}

\section{Background}

Variable number tandem repeats (VNTRs) are increasingly widely used as molecular markers in prokaryotes. More recently, attention has turned towards examining the pos- sible functional significance of these tandem repeats, especially that of microsatellites, which are often found outside coding regions, [1-7]. Moreover, the biological significance of intragenic tandem repeats, located within 
coding regions, has been demonstrated for particular genes [8-11]. With the explosion of available bacterial genomic sequences it has become clear that most, if not all, bacterial genomes contain a considerable number of intragenic tandem repeats $[12,13]$. The finding that intragenic tandem repeats are so widespread in prokaryotes suggests that the few cases documented so far may be only the tip of the iceberg and that some of the many uncharacterized tandem repeats in bacteria possibly play functional roles in pathogenesis and/or in adaptation to environmental stresses.

Here we have investigated the presence and distribution of tandemly repeated sequences in the genome of the opportunistic pathogen, Legionella pneumophila, the etiological agent of Legionnaires' disease. This microorganism flourishes naturally in fresh water environments, but is also frequently found in artificial water systems, which are considered the main source of Legionella infections in humans [14]. The L. pneumophila species comprises over 15 serogroups, of which serogroup 1 is responsible for the majority of human infections. While these Gram-negative bacteria can multiply free-living in culture, it is now widely accepted that intracellular replication in amoebic hosts such as Acanthamoeba, Naegleria, or Hartmanella is essential for the propagation and dissemination of $L$. pneumophila [15]. Industrial settings, altered lifestyle, and a growing number of elderly and immunocompromised individuals have led to an increase in number of reported L. pneumophila infections, which occur following inhalation of contaminated aerosols. When $L$. pneumophila reach the lungs, they are ingested by alveolar macrophages wherein they replicate and which they finally destroy. Ultimately host cell lysis and cell death, as well as the extracellular or surface-associated action of bacterial degradative enzymes, result in damage of lung tissue. L. pneumophila infections end in an acute and severe, often fatal, pneumonia, if not quickly and correctly diagnosed.

Two recent studies have examined tandem repeats in $L$. pneumophila as a way to discriminate between closely related strains. However, these studies have not differentiated between intergenic and intragenic repeats $[16,17]$. In addition, researchers studying individual virulence factors in $L$. pneumophila have noted the presence of repeats in these genes, and have suggested possible functional roles for the repeats $[18,19]$. In this study, we have identified and characterized the tandem repeat variations between 115 strains of $L$. pneumophila serogroup 1, collected from a wide variety of environments and patients.

\section{Methods \\ Origin of bacterial strains and growth conditions}

Lab strains 130 b (Klaus Heuner, University of Wurzburg, Germany), Corby (K. Heuner), Lens (Carmen Buchreiser,
Institut Pasteur, and CNRS URA, France), and Paris (C. Buchreiser), were obtained from the indicated labs and the Philadelphia strain was obtained from the American Tissue Culture Collection (ATCC). Strains S03, S1, S18, S3, S32, S66, S71, and S88 were isolated via filtration and selective plating from natural water sources collected at different sites throughout Belgium (kind gift of Dr. Priscilla Declerck, Katholieke Universiteit Leuven, Belgium)(unpublished). Strains IMC 1, 5, 16, and 23 were isolated from water taps, air conditioning units, and incubators in a pediatric hospital in Portugal (kind gift of Dr. Milton S. da Costa, University of Coimbra, Portugal) [20]. The 12 "LEA/LE" strains were isolated and serotyped in our laboratory from heat or acid treated swimming water samples (natural and manmade) collected throughout Belgium (kind gift of Dr. Rudy Calders, Provincial Institute for Hygiene, Antwerp, Belgium). The 18 "L" strains were isolated from various manmade environmental water sources (cooling towers, air conditioning units, pipes, irrigation hydrants, showers, water tanks, and fountains) in Spain (kind gift of Dr. Fernando Gonzalez Candelas, University of Valencia, Spain) [21,22]. Strains MGAS-357, MGAS-637, and MGAS-670 were isolated from sputum samples of sporadic clinical infection cases in Belgium (kind gift of Dr. Jan Verhaegen, University Hospital Gasthuisberg, Belgium)(unpublished). Strain HRD-4 was isolated from a sputum samples in Portugal (Dr. Milton S. da Costa)(unpublished). Strains give the "BEL" designation were isolated from sputum samples of clinical infections during three different outbreaks of Legionella in Belgium (kind gift of Dr. Marc Struelens, Free University of Brussels, Belgium)(unpublished). Strains ITA-5 and ITA-12 represent two unrelated communityacquired Legionella infections from Italy (kind gift of Dr. Isabella Marchesi, University of Modena and Reggio Emilia, Modena, Italy)([23] and unpublished). The 33 "HL" and 6 "LG" strains were isolated from sporadic, epidemic, and endemic patient infections throughout France (National Reference Center on Legionellae, Lyon, France) $([24,25]$ and unpublished). The 17 "hot springs" strains (ALF, ED, IZ, NMEX, SG) were isolated from boreholes and hot spring runoffs in Portugal and the U.S.A. with a median temperature of $42^{\circ} \mathrm{C}$ (Dr. Milton S. da Costa) $[26,27]$.

Unless otherwise described, all established L. pneumophila strains were grown at $37^{\circ} \mathrm{C}$ and $5 \% \mathrm{CO}_{2}$ in buffered yeast extract broth containing $\alpha$-ketoglutarate (BYE- $\alpha$ ) or on buffered charcoal yeast extract broth plates containing $\alpha$ ketoglutarate (BCYE- $\alpha$ ) and supplemented with Lcysteine and ferric pyrophosphate [28]. All strains were stored as glycerol stocks at $-80^{\circ} \mathrm{C}$ and thawed fresh for genomic DNA isolations. For "stress" experiments, cultures of the Philadelphia strain were grown on BCYE- $\alpha$ plates (replated every $3-4$ days) at $27^{\circ} \mathrm{C}, 37^{\circ} \mathrm{C}$ (without 
$\mathrm{CO}_{2}$ ), $37^{\circ} \mathrm{C}$ (with $\mathrm{CO}_{2}$ ) and $42^{\circ} \mathrm{C}$ (without $\mathrm{CO}_{2}$ ) for three months. This work was carried out with permission of the K.U. Leuven Biosafety Council and according to the EU directive 93/88 and 90/219/EC.

\section{Genomic DNA isolation}

Strains were grown overnight in a $5 \mathrm{ml}$ culture of BYE- $\alpha$. Genomic DNA was isolated from $1 \mathrm{ml}$ of this culture using a Wizard ${ }^{\oplus}$ Genomic DNA Purification Kit (Promega) according to the manufacturer's recommendations. The integrity of the DNA was assessed by agarose gel electrophoresis.

\section{PCR and sequencing}

PCR primers were designed using the Primer3 software [29] and chosen based on regions of high similarity (if possible) between the published Philadelphia, Lens, and Paris strain sequences (see Additional File 1). PCR was performed using SuperTaq DNA polymerase (HT Biotechnology) in $50 \mu \mathrm{l}$ reaction volumes. Initial denaturation at $94^{\circ} \mathrm{C}$ for 2 min was followed by 30 cycles of denaturation at $94^{\circ} \mathrm{C}$ for $30 \mathrm{~s}$, annealing at $45^{\circ} \mathrm{C}$ for $45 \mathrm{~s}$, and elongation at $72^{\circ} \mathrm{C}$ for $2 \mathrm{~min}$. The final extension step was $2 \mathrm{~min}$ at $72^{\circ} \mathrm{C}$. Products were visualized on $1 \%$ agarose gels for initial characterization. For sequencing the repeat regions directly, a larger portion of the gene was amplified from each strain and the repeat region was sequenced by VIB Genetic Service Facility, Antwerp, Belgium. Repeats were counted from these sequences using "Tandem Repeats Finder" [30]. Sequence-based typing of all strains except for L430-L2006 was performed using the seven gene method as previously described [31,32]. Strains L430L2006 were already typed using the older six gene method $[21,22]$.

\section{Results \\ In silico screening of the Legionella pneumophila genome for intragenic tandemly repeated sequences}

The Legionella pneumophila serogroup 1 Philadelphia strain [33] published sequence (GenBank accession no. AE017354) was screened for intragenic tandem repeats using the EMBOSS(ETANDEM) software [34]. This resulted in the identification of 85 ORFS containing 95 tandemly repeated sequences. From this list a repeat was considered significant if it met at least one of the following three criteria: the E-tandem score was greater than 50 , repeat conservation was greater than $85 \%$, or the size of the repeat was greater than $100 \mathrm{bp}$ and was present in three or more copies. Following this analysis, 39 tandem repeats remained, of which 13 were annotated in the published genome sequence only as "Hypothetical Protein" and discarded from analysis on the basis of the difficulty of assigning putative functions for subsequent analyses and choice as targets for future experiments. The remaining 26 tandem repeats were contained within 23 ORFS and were analyzed further. These 26 repeats ranged in size from 9 bp to 261 bp and were found in copy numbers ranging from 3-19 copies (Table 1 ). The length of every repeat was divisible by 3 , consistent with a strong selective pressure for repeat expansion/deletion to maintain the reading frame.

\section{Functional categorization of genes containing tandem repeats}

The 23 genes were examined with respect to their subcellular localization using the bacterial protein localization prediction program, PSORTb v.2.0 [35]. These results were compared to the overall subcellular localization predictions of the entire L. pneumophilia Philadelphia proteome (Table 2). In general, the genes containing tandem repeats appear to broadly reflect the overall distribution of proteins within a cell, with the exception of a lower proportion of inner membrane proteins, and a higher proportion of periplasmic and extracellular proteins. The increase in the proportion of extracellular proteins is due to the presence of several proteins from the tetratricopeptide repeat (TPR) repeat family (LPG1062, LPG1172, LPG1356, LPG2222) and "enhanced entry protein C" (EnhC, LPG2639) all of which contain multiple copies of a 108 bp repeat (Table 1 ). This family of "eukaryotic-like" proteins is known to encode both Sel-1 (SLR) and TPR repeat motifs within L. pneumophilia [19,36]. Furthermore, these SLR regions are thought to play important roles in protein-protein interactions required for virulence in Legionella $[19,37]$, and EnhC has been recently shown to be conserved in virtually every $L$. pneumophila species examined [25] and to play a role in intracellular growth within macrophages [38].

\section{PCR characterization of repeat variability between strains} In order to determine if a particular repeat was "polymorphic" or "monomorphic", we screened a panel of 47 different L. pneumophilia serogroup 1 strains by PCR using primers designed to flank the 26 repeat regions described above. These strains included common lab strains, clinical isolates and environmental isolates (see Methods). Of the 26 repeats, 7 were found to be polymorphic (LPG1038, LPG1299, LPG1555, LPG2224, LPG2416, LPG2644, LPG2793). At the sequence level, the internal conservation of these polymorphic repeats was, on average, higher than that of the monomorphic repeats (unpaired $t$-test, $\mathrm{p}$ value .0021), as observed previously [12]. Genes LPG1299, LPG2644, and LPG2793 correspond to the previously characterized VNTR markers Lpms35, Lpms31, and Lpms3 respectively [17]. Of the genes that were polymorphic, LPG1038, LPG1555, LPG2224, LPG2416, and LPG2793 each possessed only 2 or 3 alleles whereas LPG1299 possessed 22 alleles. The repeat region for gene LPG2644 possesses 12 alleles and more data about LPG2644 and its encoded protein will be described in 
Table I: Genes containing intragenic tandem repeat arrays in the Philadelphia strain

\begin{tabular}{|c|c|c|c|c|}
\hline Gene & Length of repeat (bp) & Copy number & Identity† (\%) & Genome annotation $\ddagger$ \\
\hline LPG045I* & 30 & 18 & 75.6 & IcmE (DotG) \\
\hline LPG045I* & 30 & 7 & 72.9 & IcmE (DotG) \\
\hline LPG0688 & 9 & 5 & 88.9 & Hsp60, $60 \mathrm{~K}$ Heat shock protein \\
\hline LPGI035 & 102 & 3 & 93.8 & Copper efflux ATPase copA2 \\
\hline LPG 1038 & 12 & 4 & 89.6 & Vrrb \\
\hline LPGI062 & 108 & 8 & 71.1 & TPR repeat protein \\
\hline LPGII72* & 108 & 8 & 69.9 & TPR repeat protein \\
\hline LPGII72* & 108 & 4 & 75.0 & TPR repeat protein \\
\hline LPG I 299 (Lpms35)§ & 18 & 3 & 87.0 & Transmembrane Tfp pilus assembly protein FimV \\
\hline LPGI356* & 108 & 4 & 72.2 & TPR repeat protein \\
\hline LPGI356* & 108 & 3 & 74.4 & TPR repeat protein \\
\hline LPG 1421 & 261 & 3 & 71.4 & 30S Ribosomal protein SI \\
\hline LPG I555 & 21 & 2 & 100 & Arginine $3 r d$ transport system periplasmic binding protein Art \\
\hline LPG I 602 & 90 & 10 & 65.1 & FLJ00I80 protein \\
\hline LPG 1948 & 90 & 7 & 75.6 & FLJ00I80 protein \\
\hline LPG 1958 & 87 & 13 & 74.3 & FLj00I80 protein \\
\hline LPG 1976 & $17 \mid$ & 3 & 73.7 & UVB-resistance protein UVR8 \\
\hline LPG2222 & 108 & 6 & 70.7 & TPR repeat protein, protein-protein interaction \\
\hline LPG2224 & $17 \mid$ & 5 & 73.5 & UVB-resistance protein UVR8 \\
\hline LPG2392 & 87 & 6 & 72.2 & Leucine rich repeat protein family \\
\hline LPG24I6 & 105 & 3 & 81.9 & Ankyrin repeat family protein \\
\hline LPG2485 & 102 & 9 & 58.5 & TPR domain protein \\
\hline LPG2559 & 12 & 4 & 91.7 & ATP-dependant DNA helicase RecG \\
\hline LPG2639 & 108 & 5 & 65.9 & Enhanced entry protein EnhC \\
\hline LPG2644 (Lpms3I)§ & 45 & 19 & 85.4 & $\overline{T a i l}$ fiber protein ScIB (collagen-like) \\
\hline LPG2793 (Lpms3)§ & 96 & 7 & 74.0 & LepA, interaptin \\
\hline
\end{tabular}

*Genes containing two distinct repeat arrays. †Percentage identity between repeats. $\ddagger$ All gene annotations are from the published sequence of Legionella pneumophila, Philadelphia strain (GenBank accession no. AE0I7354). §Annotation used in MLVA typing scheme proposed by [17]. IcmE: intracellular multiplication protein E, DotG: defect in organelle trafficking protein G, Vrrb: variable region with repetitive sequence B, TPR: tetratricopeptide repeat, FimV: fimbriae protein V, Tfp: type IV pili, ScIB: Streptococcus pyogenes collagen-like protein B, LepA: Legionella effector protein A.

detail elsewhere (Vandersmissen, L., Coil, D.A., De Buck, E., Lammertyn, E., Anné, J. submitted for publication).

\section{Patterns of repeat variation}

These 7 repeats were further examined in an additional 106 strains, for a total of 153 strains, divided into four strain groups: lab strains $(n=5)$, environmental strains ( $n$ $=59)$, clinical strains $(n=65)$, and hot springs strains ( $\mathrm{n}$ $=24$ ). However, lab strains were not considered for any subsequent statistical analyses. We next performed sequence-based typing on all 153 strains in order to examine the relatedness of the strains. Strains were excluded if they were collected from the same site and possessed both the same SBT type and the same pattern of tandem repeat variation. This resulted in the removal of 38 strains from our analysis, leaving 42 environmental strains, 51 clinical strains, and 17 hot springs strains for a total of 115 strains (see Additional File 2).

The average number of repeats for each gene was calculated across each of the three remaining categories of strains (Table 3 ). The data was found to have unequal variance between categories (Levene's test), therefore the means were compared using a two-tailed heteroscedastic t-test (Table 3). From a clinical perspective, the most important comparison is between the environmental and

Table 2: Subcellular localization of proteins containing tandem repeats

\begin{tabular}{|c|c|c|c|}
\hline & L. pneumophila Philadelphia proteome $(\mathrm{n}=294 \mathrm{I})$ & Proteins containing repeats $(n=23)$ & $X^{2} \mathrm{p}$-value \\
\hline Cytoplasmic & $31.1 \%(n=915)$ & $21.7 \%(n=5)$ & 0.33 \\
\hline Inner Membrane & $18.2 \%(n=534)$ & $0 \%(n=0)$ & 0.024 \\
\hline Extracellular & $0.8 \%(n=22)$ & $21.7 \%(n=5)$ & $<.0001$ \\
\hline Outer Membrane & $1.8 \%(n=53)$ & $4.3 \%(n=1)$ & 0.359 \\
\hline Periplasm & $1.2 \%(n=36)$ & $8.7 \%(n=2)$ & 0.001 \\
\hline Unknown & $46.9 \%(n=1381)$ & $43.4 \%(n=10)$ & 0.738 \\
\hline
\end{tabular}


Table 3: Comparison of average tandem repeat copy number between strain types

\begin{tabular}{|c|c|c|c|c|c|c|c|c|}
\hline \multirow[t]{5}{*}{$\mathbf{A}$} & \multirow[b]{2}{*}{ Gene } & \multicolumn{7}{|c|}{ Average number of repeats } \\
\hline & & 1038 & 1299 & 1555 & 2224 & 2416 & 2644 & 2793 \\
\hline & Environmental $(\mathrm{E})$ & 2.78 & 14.52 & 1.02 & 4.40 & 2.04 & 11.80 & 6.19 \\
\hline & Clinical (C) & 3.5 & 17.78 & 1.10 & 4.71 & 2.28 & 12.70 & 6.45 \\
\hline & Hot springs $(H)$ & 3.00 & 9.65 & 1.00 & 5.00 & 2.41 & 14.12 & 7.00 \\
\hline \multirow[t]{4}{*}{ B } & & \multicolumn{7}{|c|}{ Student t-test p-values } \\
\hline & E versus $C$ & 0.0003 & 0.029 & 0.13 & 0.34 & 0.0097 & 0.15 & 0.044 \\
\hline & E versus $\mathrm{H}$ & 0.096 & 0.0014 & 0.32 & 0.070 & 0.011 & $<.0001$ & $<.0001$ \\
\hline & $\mathrm{C}$ versus $\mathrm{H}$ & 0.0011 & $<.0001$ & 0.024 & 0.17 & 0.36 & 0.0014 & $<.0001$ \\
\hline
\end{tabular}

*Values in bold were considered significant $(\mathrm{p}<.05)$. The mean of each population (Environmental, $\underline{\text { Clinical, }}$ Hot Springs) was compared using a two-tailed heteroscedastic $t$-test.

clinical samples. Genes LPG1038, LPG1299, LPG2416 and LPG2793 all exhibited significant differences in repeat distribution between clinical and environmental isolates. In all of these cases repeat numbers were higher in the clinical samples than in the environmental samples.

\section{Stability of repeat number}

Most tandemly repeated sequences are known to be able to mutate at a faster rate than non-tandemly repeated sequences (for a recent review, see [39]). Therefore, we were interested in examining the stability of these repeats over time, to ensure that our data do not simply represent a "snapshot" in time of repeat copy number in these strains. We began by serially passaging identical cultures of the Philadelphia strain at various temperatures for three months (see Methods). At the end of this period, we measured the repeat copy number in each of the 26 candidate repeat arrays and found that none of them had varied over this time span (data not shown). Because two of the 23 candidate genes are involved in UVB resistance (Table 1) we also examined the stability of these two repeats under repeated exposure to UV light. Plates of Philadelphia strain were exposed to varying lengths (30, $60,120,240$ seconds) of UVB radiation just after streaking at each passage ( $\sim$ every 3 days). While there was a noticeable effect on survival of the bacteria, after 10 generations no changes in repeat number were observed for either LPG1976 or LPG2224 (data not shown).

\section{Discussion}

While bacteria in general appear to have a large number of tandem repeats, the possible phenotypic effects of intragenic repeats are only beginning to be examined. Evidence exists from other organisms that variable number tandem repeats are involved in the evolution of new genes, gene regulation, adaptation, resistance to environmental stresses, and avoidance of the immune system. In this work, we have investigated the presence and variability in copy number of tandemly repeated sequences in the genome of L. pneumophila, an important human pathogen and model for the study of host-pathogen interactions. We have identified 23 genes containing tandem repeats and determined that seven of them exhibited variability in repeat copy number between strains.

More importantly, we have demonstrated that the distribution of repeat variation is significantly non-random in L. pneumophila and therefore may have functional implications. Our results suggest that the number of intragenic tandem repeats found within most genes varies as a function of strain origin. Six of the seven genes examined display distinctive differences between the three groups of strains examined (environmental, clinical, and hot springs). In particular, four genes exhibit significant differences in repeat copy number between environmental and clinical samples. Moreover, for three of the four genes, the distribution of repeat copy number is also significant between clinical samples and hot springs samples, further highlighting the potential significance of the higher repeat copy number found in clinical samples for these genes.

One possible complication with an experiment of this nature is the rate of change of repeat copy number. While a variety of studies have been undertaken examining the mechanism and stability of tandem repeats, none of them addressed intragenic tandem repeats in particular and most have focused on smaller microsatellites (1-6 bp) [39]. In our hands, none of these larger repeats changed in copy number through multiple generations under a variety of conditions. While these conditions do not accurately substitute for a competitive natural environment, these experiments do suggest that intragenic repeat number is reasonably stable over time.

The four genes which exhibit significant differences in repeat copy number between environmental and clinical samples are of particular interest from a clinical perspec- 
tive since tandem repeats in these genes could play roles in the pathogenesis of L. pneumophila. LPG1038 is annotated as "vrrb" in the published sequence, however we have been unable to verify any nucleotide or protein homology with the "variable region with repetitive sequence B" (vrrb) gene from Bacillus anthracis [40]. Furthermore, BLAST searches with this sequence do not produce any significant hits other than those from the published L. pneumophila sequences. It is therefore possible that this gene may represent a novel virulence factor in which tandem repeats could play a functional role. LPG1299 is homologous to the fimV gene described in Pseudomonas aeruginosa [41]. This gene is thought to be involved in twitching motility, possibly through the remodeling of the peptidoglycan layer to enable assembly of type IV pili. Twitching motility is known to be important in the virulence of $P$. aeruginosa, however it has not yet been described in L. pneumophila. LPG2416 is a gene of unknown function but contains an ankyrin repeat sequence, thought to mediate protein-protein interactions [42], and which have been recently demonstrated to play a role in the manipulation of L. pneumophila host physiology and infection $[37,43,44]$. Lastly, LPG2793 encodes an effecter of the Icm/Dot type IV secretion system and is known to play a role in the release of $L$. pneumophila from a protozoan host $[45,46]$.

\section{Conclusion}

Overall, our results provide a detailed examination of variable intragenic tandem repeat distribution as a function of strain origin. These data suggest a potential functional role of tandem repeats in adaptation to different environments. Current work is focused on understanding the exact role that intragenic tandem repeats play in particular genes.

\section{Authors' contributions}

DAC helped design the study, carried out the experiments, analyzed the data, and drafted the manuscript. LV participated in the design of the study, the in silico analysis, and performed some of the PCR and sequencing. CG and SJ performed the SBT typing of all strains. EL conceived of the study and assisted with the in silico analysis. JA participated in the design and coordination of the study and helped to write the manuscript. All authors read and approved the final manuscript.

\section{Additional material}

\section{Additional file 1}

PCR Primers used in this study. This file lists all of the PCR primers used for tandem repeat amplification in this study.

Click here for file

[http://www.biomedcentral.com/content/supplementary/1471-

2180-8-218-S1.pdf]

\section{Additional file 2}

Repeat and SBT information for all strains. This table contains the tandem repeat copy number and SBT type for all 115 strains used in the final analysis.

Click here for file

[http://www.biomedcentral.com/content/supplementary/1471-

2180-8-218-S2.xls]

\section{Acknowledgements}

We would like to thank Dr. Isabelle Henry for help with data analysis and for critical review of the manuscript. DAC is supported by a BOF fellowship (KU Leuven Onderzoeksfonds PDM/F/07/038). This work was further financed by grants OT/05/62 from KU Leuven Onderzoeksfonds and G.0289.06 from Research Foundation - Flanders (FWO).

\section{References}

I. Bayliss $C D$, Field D, Moxon ER: The simple sequence contingency loci of Haemophilus influenzae and Neisseria meningitidis. J Clin Invest 200I, 107(6):657-662.

2. Li YC, Korol AB, Fahima T, Nevo E: Microsatellites within genes: structure, function, and evolution. Mol Biol Evol 2004, 21(6):991-1007.

3. van Belkum A, Scherer S, van Alphen L, Verbrugh H: Shortsequence DNA repeats in prokaryotic genomes. Microbiol Mol Biol Rev 1998, 62(2):275-293.

4. van Belkum A, Scherer S, van Leeuwen W, Willemse D, van Alphen $\mathrm{L}$, Verbrugh $\mathrm{H}$ : Variable number of tandem repeats in clinical strains of Haemophilus influenzae. Infect Immun 1997, 65(I 2):5017-5027.

5. van Belkum A, van Leeuwen W, Scherer S, Verbrugh H: Occurrence and structure-function relationship of pentameric short sequence repeats in microbial genomes. Res Microbiol 1999 , I50(9-10):617-626.

6. Woude $M W$ van der, Baumler AJ: Phase and antigenic variation in bacteria. Clin Microbiol Rev 2004, I7(3):58I-6II. table of contents

7. Bayliss CD, Dixon KM, Moxon ER: Simple sequence repeats (microsatellites): mutational mechanisms and contributions to bacterial pathogenesis. A meeting review. FEMS Immunol Med Microbiol 2004, 40(I): I - 19.

8. Citti C, Kim MF, Wise KS: Elongated versions of Vlp surface lipoproteins protect Mycoplasma hyorhinis escape variants from growth-inhibiting host antibodies. Infect Immun 1997, 65(5): $1773-1785$.

9. Weiser JN, Pan N: Adaptation of Haemophilus influenzae to acquired and innate humoral immunity based on phase variation of lipopolysaccharide. Mol Microbiol 1998, 30(4):767-775.

10. Wilton JL, Scarman AL, Walker MJ, Djordjevic SP: Reiterated repeat region variability in the ciliary adhesin gene of Mycoplasma hyopneumoniae. Microbiology 1998, I44(Pt 7): 193 I- 1943.

II. Yang Y, Gabriel DW: Intragenic recombination of a single plant pathogen gene provides a mechanism for the evolution of new host specificities. J Bacteriol 1995, I77(17):4963-4968.

12. Denoeud F, Vergnaud G: Identification of polymorphic tandem repeats by direct comparison of genome sequence from different bacterial strains: a web-based resource. BMC Bioinformatics 2004, 5:4.

13. Le Fleche P, Hauck Y, Onteniente L, Prieur A, Denoeud F, Ramisse V, Sylvestre $P$, Benson G, Ramisse F, Vergnaud G: A tandem repeats database for bacterial genomes: application to the genotyping of Yersinia pestis and Bacillus anthracis. BMC Microbiol 200I, $\mathrm{I}: 2$.

14. Fields BS, Benson RF, Besser RE: Legionella and Legionnaires' disease: 25 years of investigation. Clin Microbiol Rev 2002, I5(3):506-526.

15. Steinert M, Hentschel U, Hacker J: Legionella pneumophila: an aquatic microbe goes astray. FEMS Microbiol Rev 2002, 26(2): 149-162. 
16. Pourcel C, Vidgop Y, Ramisse F, Vergnaud G, Tram C: Characterization of a tandem repeat polymorphism in Legionella pneumophila and its use for genotyping. I Clin Microbiol 2003, 4I(5):18I9-|826.

17. Pourcel C, Visca P, Afshar B, D'Arezzo S, Vergnaud G, Fry NK: Identification of variable-number tandem repeat sequences in Legionella pneumophila and development of an optimized MLVA typing scheme. J Clin Microbiol 2007, 45(4): I 190-II 99.

18. D'Auria G, Jimenez N, Peris-Bondia F, Pelaz C, Latorre A, Moya A: Virulence factor $r t x$ in Legionella pneumophila, evidence suggesting it is a modular multifunctional protein. BMC Genomics 2008, 9(I): 14

19. Newton HJ, Sansom FM, Dao J, McAlister AD, Sloan J, Cianciotto NP, Hartland EL: Sell repeat protein LpnE is a Legionella pneumophila virulence determinant that influences vacuolar trafficking. Infect Immun 2007, 75( I 2):5575-5585.

20. Verissimo A, Vesey G, Rocha GM, Marrao G, Colbourne J, Dennis PJ, da Costa MS: A hot water supply as the source of Legionella pneumophila in incubators of a neonatology unit. J Hosp Infect 1990, 15(3):255-263.

21. Coscolla M, Gonzalez-Candelas F: Population structure and recombination in environmental isolates of Legionella pneumophila. Environ Microbiol 2007, 9(3):643-656.

22. Coscolla M, Gosalbes MJ, Catalan V, Gonzalez-Candelas F: Genetic variability in environmental isolates of Legionella pneumophila from Comunidad Valenciana (Spain). Environ Microbiol 2006, 8(6): 1056-1063.

23. Borella P, Marchesi I, Boccia S, Amore R, Cagarelli R, Casolari C, Marchegiano P: Epidemiological investigation on a suggestive case of Legionella pneumonia and public health implications. Scand J Infect Dis 2006, 38(8):725-728.

24. Aurell H, Farge P, Meugnier H, Gouy M, Forey F, Lina G, Vandenesch $F$, Etienne J, Jarraud S: Clinical and environmental isolates of Legionella pneumophila serogroup I cannot be distinguished by sequence analysis of two surface protein genes and three housekeeping genes. Appl Environ Microbiol 2005, 7I(I):282-289.

25. Cazalet C, Jarraud S, Ghavi-Helm Y, Kunst F, Glaser P, Etienne J, Buchrieser C: Multigenome analysis identifies a worldwide distributed epidemic Legionella pneumophila clone that emerged within a highly diverse species. Genome Res 2008, 18(3):43।-44I.

26. Verissimo A, Marrao G, da Silva FG, da Costa MS: Distribution of Legionella spp. in hydrothermal areas in continental Portugal and the island of Sao Miguel, Azores. Appl Environ Microbiol 1991, 57(10):2921-2927.

27. Marrao G, Verissimo A, Bowker RG, da Costa MS: Biofilms as major sources of Legionella spp. in hydrothermal areas and their dispersion into stream water. FEMS Microbiology Ecology 1993, 12:25-33.

28. Edelstein PH, Edelstein MA: Comparison of three buffers used in the formulation of buffered charcoal yeast extract medium. J Clin Microbiol I993, 3 I( I 2):3329-3330.

29. Rozen S, Skaletsky H: Primer3 on the WWW for general users and for biologist programmers. Methods Mol Biol 2000, 132:365-386.

30. Benson G: Tandem repeats finder: a program to analyze DNA sequences. Nucleic Acids Res 1999, 27(2):573-580.

31. Gaia V, Fry NK, Afshar B, Luck PC, Meugnier H, Etienne J, Peduzzi R, Harrison TG: Consensus sequence-based scheme for epidemiological typing of clinical and environmental isolates of Legionella pneumophila. J Clin Microbiol 2005, 43(5):2047-2052.

32. Ratzow S, Gaia V, Helbig JH, Fry NK, Luck PC: Addition of neuA, the gene encoding $\mathbf{N}$-acylneuraminate cytidylyl transferase, increases the discriminatory ability of the consensus sequence-based scheme for typing Legionella pneumophila serogroup I strains. J Clin Microbiol 2007, 45(6): 1965-I968.

33. Chien M, Morozova I, Shi S, Sheng H, Chen J, Gomez SM, Asamani G, Hill K, Nuara J, Feder M, Rineer J, Greenberg JJ, Steshenko V, Park SH, Zhao B, Teplitskaya E, Edwards JR, Pampou S, Georghiou A, Chou IC, lannuccilli W, Ulz ME, Kim DH, Geringer-Sameth A, Goldsberry C, Morozov P, Fischer SG, Segal G, Qu X, Rzhetsky A, Zhang P, Cayanis $E$, De Jong PJ, Ju J, Kalachikov S, Shuman HA, Russo J]: The genomic sequence of the accidental pathogen Legionella pneumophila. Science 2004, 305(5692): 1966-1968.
34. Rice P, Longden I, Bleasby A: EMBOSS: the European Molecular Biology Open Software Suite. Trends Genet 2000, 16(6):276-277.

35. Gardy JL, Laird MR, Chen F, Rey S, Walsh CJ, Ester M, Brinkman FS PSORTb v.2.0: expanded prediction of bacterial protein subcellular localization and insights gained from comparative proteome analysis. Bioinformatics 2005, 21(5):617-623.

36. Albert-Weissenberger C, Cazalet C, Buchrieser C: Legionella pneumophila - a human pathogen that co-evolved with fresh water protozoa. Cell Mol Life Sci 2007, 64(4):432-448.

37. Cazalet $C$, Rusniok C, Bruggemann H, Zidane N, Magnier A, Ma L, Tichit M, Jarraud S, Bouchier C, Vandenesch F, Kunst F, Etienne J, Glaser P, Buchrieser C: Evidence in the Legionella pneumophila genome for exploitation of host cell functions and high genome plasticity. Nat Genet 2004, 36( I I): I I65- I I73.

38. Liu M, Conover GM, Isberg RR: Legionella pneumophila EnhC is required for efficient replication in tumor necrosis factor alpha-stimulated macrophages. Cell Microbiol 2008, IO(9): 1906-1923.

39. Bichara M, Wagner J, Lambert IB: Mechanisms of tandem repeat instability in bacteria. Mutat Res 2006, 598(I-2): 144-163.

40. Keim P, Price LB, Klevytska AM, Smith KL, SchupP JM, Okinaka R, Jackson PJ, Hugh-Jones ME: Multiple-locus variable-number tandem repeat analysis reveals genetic relationships within Bacillus anthracis. J Bacteriol 2000, I 82(10):2928-2936.

4I. Semmler AB, Whitchurch CB, Leech AJ, Mattick JS: Identification of a novel gene, fimV, involved in twitching motility in Pseudomonas aeruginosa. Microbiology 2000, I 46(Pt 6): | 32 |-| 332.

42. Li J, Mahajan A, Tsai MD: Ankyrin repeat: a unique motif mediating protein-protein interactions. Biochemistry 2006, 45(5I): $15168-15178$.

43. Habyarimana F, Al-Khodor S, Kalia A, Graham JE, Price CT, Garcia MT, Kwaik YA: Role for the Ankyrin eukaryotic-like genes of Legionella pneumophila in parasitism of protozoan hosts and human macrophages. Environ Microbiol 2008, I0(6): | 460-I 474.

44. Pan X, Luhrmann A, Satoh A, Laskowski-Arce MA, Roy CR: Ankyrin repeat proteins comprise a diverse family of bacterial type IV effectors. Science 2008, 320(5883): $165|-| 654$.

45. Chen J, de Felipe KS, Clarke M, Lu H, Anderson OR, Segal G, Shuman HA: Legionella effectors that promote nonlytic release from protozoa. Science 2004, 303(5662): |358-|36|.

46. Chen J, Reyes M, Clarke M, Shuman HA: Host cell-dependent secretion and translocation of the LepA and LepB effectors of Legionella pneumophila. Cell Microbiol 2007, 9(7): 1660-167I.

Publish with BioMed Central and every scientist can read your work free of charge

"BioMed Central will be the most significant development for disseminating the results of biomedical research in our lifetime. "

Sir Paul Nurse, Cancer Research UK

Your research papers will be:

- available free of charge to the entire biomedical community

- peer reviewed and published immediately upon acceptance

- cited in PubMed and archived on PubMed Central

- yours - you keep the copyright 